\title{
Cloud-based Production Logistics Synchronization Mechanism and Method
}

\author{
ShuiPing Lei ${ }^{1, *}$, Ting $\mathrm{Qu}^{1}$, ZongZhong Wang ${ }^{1}$, Xin $\mathrm{Chen}^{1}$, Hao $\mathrm{Luo}^{2}$, and George Q. \\ Huang $^{3}$ \\ ${ }^{1}$ Guangdong CIMS Key Lab, Guangdong University of Technology, Guangzhou, PR China. \\ leifeitian@126.com, \{quting, wangzz, chenx\}@gdut.edu.cn \\ ${ }^{2}$ College of Economics, Shenzhen University, Shenzhen, PR China. \\ luohaoeszu.edu.cn \\ ${ }^{3}$ Department of Industrial and Manufacturing Systems Engineering, The University of Hong \\ Kong, PR China. \\ gqhuang@hku.hk
}

\begin{abstract}
It is inevitable that the dynamic is occurs in the operation of the production logistics (PL). Production logistics synchronization (PLS) can solve the dynamic of production logistics operation process by collaboration the both or among of the production, shipping and storage. Cloud manufacturing mode can quickly respond to the shortage of resources in the production logistics operation process, and provide cheap cloud resource services, such as cloud forklift. This paper is aimed at the problem for the dynamic of production logistics operation, and the dynamic of production logistics is classified. The PLS mechanism and cloud-based PLS information framework are established. By using collaboration optimization $(\mathrm{CO})$ method, the optimization method of PLS is put forward. Finally, the PLS optimization model of production and storage is presented with an industrial case, and the effectiveness is also demonstrated and analyzed.
\end{abstract}

Keywords: Production logistic synchronization; Dynamics; Cloud manufacturing; Collaborative optimization.

\section{Introduction}

Production logistics (PL) refers to the warehousing, packaging, transportation, and other logistics-related activities which directly serves for production processes, ranging from raw materials purchasing, shop-floor manufacturing, as well as the circulation of semi-finished or finished products [1]. Production logistics is divided into the pre-production logistics (storage, shipping, production) and post-production logistics (production, shipping, storage). Production logistics of this paper is specifically for the postproduction logistics. Inevitable uncertain factors of production logistics operation pro- 
cess (such as emergency order, delivery in advance, equipment failure and worker absenteeism) bring dynamics to the production logistics system, which will affect the production, shipping and storage in a part or multiple parts and lead to production logistics system is not working properly, or even stop running, which brings a great challenge to the enterprise decision-making and implementation and greatly increases time and cost of production logistics. There are two aspects impact of dynamic mainly to the production logistics system: the first is that it disrupts the original production logistics plan, and lead to the result deviates from a pre-determined goal; the second is that it sometimes leads to the lack of the ability of production logistics system resources, and it is difficult to add new resources, and the cost is very high.

Production logistics synchronization (PLS) means, in the presence of certain execution dynamics, some parts or the whole PL systems will be real-timely triggered to make adaptively collaborative decision which takes the dynamics into consideration and generates an updated execution plan for the next execution stage [2]. Therefore, under the premise of uninterrupted production logistics operation, the production, shipping and storage of the two or the three can be collaborated, and the whole of production logistics operation can be achieved optimization.

In addition, in recent years, the cloud manufacturing and related technology has provided the solution for the PL system rapid organization resources and the dynamic response of the resources requirement. Cloud manufacturing (CM) provides a serviceoriented manufacturing platform to organize the manufacturing resources over internet and enable users to consume on-demand manufacturing services [3]. In CM, various manufacturing resources and abilities can be intelligently sensed and connected into the wider internet [4]. At present, some progress has been made in the application of cloud manufacturing. $\mathrm{Xu}$ [5] encapsulates the distributed resources into $\mathrm{CM}$ services under centralized management, and offer CM services as product design, manufacturing, testing and management. Wang and $\mathrm{Xu}$ [6] proposes a service-oriented and interoperable Cloud manufacturing system. Ren et al. [7] presents a public cloud manufacturing system for small- and medium-sized enterprises (SME).

Therefore, this paper will study how to solve the impact of the dynamic production logistics system to achieve the purpose of optimizing the PL operation by CM and collaboration optimization method $[8,9]$.

The remainder of the paper is organized as follows. Section 2 will analysis for the production logistics dynamics types. Section3 will conduct the PLS mechanism. The overall PLS optimization method and mathematical model will be introduced in Section 4. Section 6 gives a case for the study the method. Conclusions are summarized in Section 7.

\section{PL Dynamics Analysis}

The different dynamics of production logistics operation have different influence on the system. To take effective method to deal with the dynamic of production logistics, we need to classify the dynamics firstly. This section will analyze the dynamic of production logistics from two aspects, which is range of impact and degree of the impact. 


\subsection{Classification in Dynamic Impact Range}

From the range of dynamic influence of the production logistics system, the dynamic of the production logistics can be differentiated into the global and partial dynamics. As shown in the left part of Figure 1, when the dynamic interfere with the three subsystems as the production, distribution, warehousing, and trigger the response of the three subsystems, which is defined the global dynamic, for example like emergency ordering, delivery changing, etc. As shown in the right part of Figure 1, when the dynamic interfere one subsystem, and this subsystem triggers the other subsystem or all of them to respond it, we call it the partial dynamic, such as workshop equipment failure, reworking, forklift failure, the road unavailable, etc.

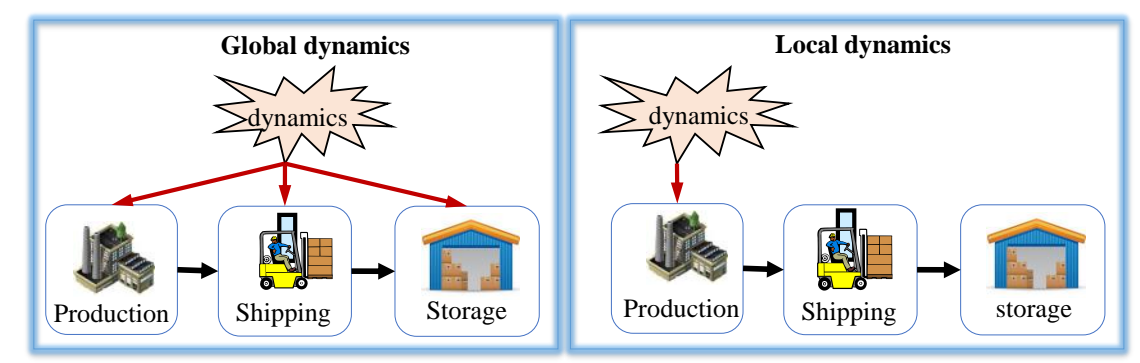

Fig. 1. Global and local dynamics

\subsection{Classification in Dynamic Impact Degree}

The sensitivity of dynamic in different time and state of production, distribution and storage is different, therefore, the impact of the dynamic on the production logistics system can be differentiated as the first level dynamics and the second level dynamics. When the dynamic affection level of the production logistics system is still in the capacity of the current resources range, we define it the first level of dynamic. For example, when forklifts increase of 10 pallets of transport tasks suddenly or a forklift failed, and the forklift resources of the system is still redundancy, so this dynamic can be cope with. When the dynamic affection level of the production logistics system is out of the current one or more subsystems resource capacity, we define it the second dynamic. For example, the current configuration of the forklift are in the saturated state, even this time increase of 1 pallets transport task urgently, it will inevitably cause the production logistics system disorder and delay delivery.

\section{PLS Mechanism}

\subsection{Synchronization Mechanism}

The PLS mechanism as shown in Figure 2. PLS can generate varied synchronization sequence while according to the quantity of different synchronization starting point and subsystem. Therefore, we need to determine the starting point and the sequence of PLS. 
The global dynamic synchronization process shown in the left of Figure 2. Firstly, we should judge the starting point of the PLS, and the basis of judging the starting point is the constraint strength of the subsystem. For example, the target of the production subsystem is to complete the order of that day, which must be completed, and the target of other subsystems is variable, in this time, the production subsystem is the starting point. Secondly, starting point to determine the synchronization sequence of production logistics and start synchronization other subsystems, such as the production synchronization shipping or shipping synchronization storage. The local dynamic synchronization process shown in the right of Figure 2. For the local dynamics do not need to determine the starting point of the synchronization, It is only a need to identify the dynamic generation point and this point is the starting point for the production of logistics synchronization, such as production, while the starting point of the synchronization from the production subsystem.
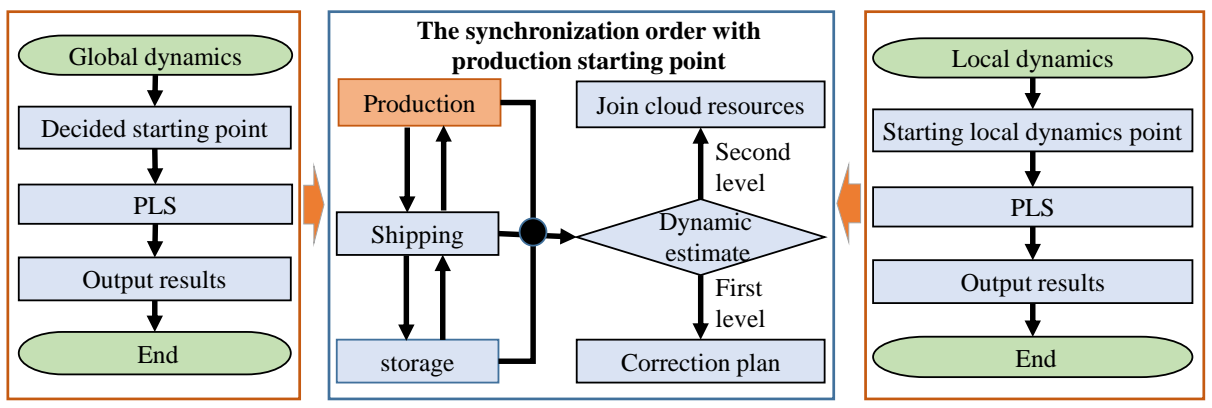

Fig. 2. PLS mechanism

The sequence is the production as the starting point, and the synchronization between shipping and storage is to describe the different dynamic levels, which contains three steps, as shown in the middle of Figure 2.

- Step 1 is dynamic level estimate. If the dynamic is the first level then execution steps 2 , else if is the second level then execution steps 3.

- $\quad$ Step 2 is to correct the plan. It is the first level dynamic processing method. This step only corrects the results of the pre-decision based on the allocated resources, such as the finished offline time, storage tasks, forklift transportation tasks, etc.

- Step 3 is to join cloud resources. This step is the second level dynamic processing method. The logistics resources can be virtualized cloud resources by cloud resource management platform, such as forklift, warehouse, production equipment, etc. Through the cloud resource platform adds cloud resources, re-planning tasks, which can solve the problem of the shortage of resources capacity caused by the dynamic.

\subsection{PLS Information framework}

Based on the above explanation, a framework is developed based on the above mentioned mechanism, which is put forward by the authors' research team [2], as shown in 
Figure 3. The bottom part of Figure 3 is the physical resource layer and the smart object layer, through equipping the physical PL resources with a series of IoT devices (such as PDA, mobile, PAD etc.) and IoT tags (such as RFID, sensor, barcode etc.), the original resources can be transformed into smart objects (PL-SO) which have the ability of real-time information perception, transmission, and task processing. The left part of Figure 3 is CM infrastructure, which defines the management, organization and service hierarchy of CM resources. It includes three layers.

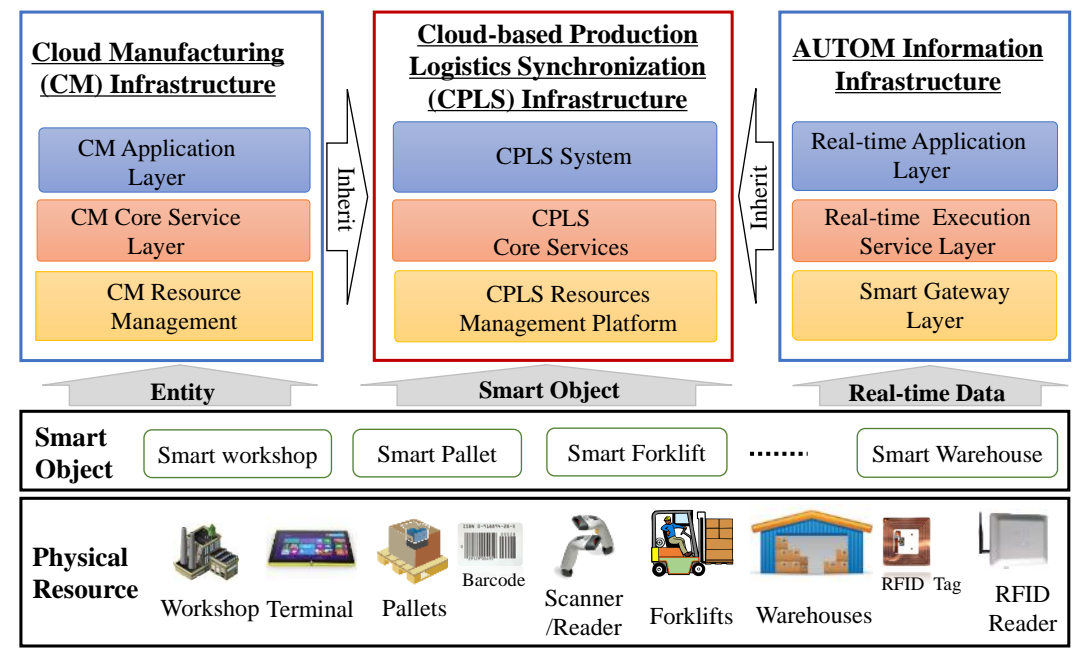

Fig. 3. Cloud-based PLS information framework

During the production logistics process, dynamically triggered two level dynamics will lead to the continuous involvement of uncertain manufacturing resources from the cloud. Due to the uncertain types, interfaces and capabilities of the various cloud resources, it is difficult to maintain a highly efficient operation. Thus, heterogeneous resources must be encapsulated by IoT technologies in a standard way, based on which a set of standards and measures for real-time information collecting, processing, and transmitting could be established. Finally, the major services and applications could be developed based on the standard real-time information to effectively support the production logistics process management. This paper extends AUTOM [10] to deal with the real-time PL information from cloud-managed PL resources. A brief representation of AUTOM is shown in the right part in Figure 3, which consists of three layers.

\section{$4 \quad$ PLS Optimization Method}

PLS is a multiple subsystems coordination optimization problems, due to the process of synchronization has emphasized the dynamics, the independence of the decisionmaking model and the agility which come from the decision-making. Collaborative optimization (CO) [11] is a kind of stratified two-layer MDO method, which has system 
level optimization function. For the subsystem, which the analysis and optimization design is within the space of each subsystem. It's suitable for the subsystem variable much more than the subject (subsystem) variable, which applies to solve the multidisciplinary design optimization problem that has the goal of system level design. Therefore, this paper uses CO to solve the PLS optimization problem.

\subsection{PLS Model}

The mathematical model of the production logistics synchronization system is established by using the $\mathrm{CO}$ optimization method as follows.

1. System level optimization model

$$
\begin{gathered}
\min f(z) \\
\text { subject to } J_{i}^{*}=\sum_{j=1}^{s_{i}}\left(z_{j}-x_{i j}^{*}\right)^{2}=0, \quad i=1,2,3
\end{gathered}
$$

The variable $J_{i}^{*}(\mathrm{z})$ is the consistency equality constraint for the system, $\mathrm{z}$ is the system optimization variable, $z_{j}$ is the design variable for the $j$ system, $s_{i}$ is the design variable quantity of the $i$ subsystem, and $x_{i j}^{*}$ represents the optimization results of the design variable $j$ of the subsystem $i$.

2. Subsystem level optimization model

$$
\begin{array}{cc}
\min J_{i}\left(x_{i}\right)= & \sum_{j=1}^{x_{i}}\left(x_{i j}-z_{j}^{*}\right)^{2}=0 \\
\text { subject to } & c_{i}\left(x_{i} \leq 0\right), \quad i=1,2,3
\end{array}
$$

The variable $x_{i}$ is design vector of the subsystem $i, x_{i j}$ is the design variable $j$ of subsystem $i, z_{j}^{*}$ is the expected value of the design variable $j$ for the system assigned to the subsystem $i$, and $c_{i}\left(x_{i}\right)$ is a system level constraint.

The optimization structure of the above mentioned mathematical model is shown in Figure 4.

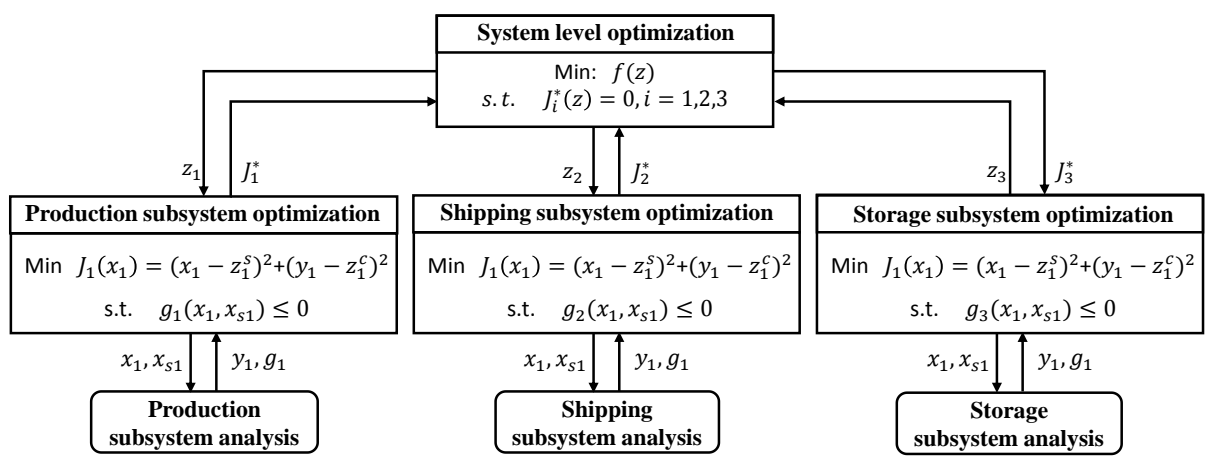

Fig. 4. Structure of production logistics collaborative optimization 


\subsection{Constraints Relaxation}

The collaboration optimization method for the consistency constraint of the system level optimization problem is the equality constraint. But the consistency of equality constraint is too strict for the subsystem. Therefore, the system level equality constraints are changed to inequality constraints, so that the system level has feasible solution domain [11]. After the deformation, the system level constraints become the following inequality.

$$
J_{I}^{*}=\sum_{j=1}^{s_{i}}\left(z_{j}-x_{i j}^{*}\right)^{2} \leq \varepsilon, i=1,2, \ldots, n
$$

Through adding the relaxation factor $\varepsilon, \varepsilon$ is smaller, which indicates a higher degree of consistency for the subsystem level, and means the performance of the cooperative optimization method is improved.

\section{$5 \quad$ Case Study}

The case company is a large-size old-brand paint making company in China. At present, the application process of the PLS optimization method is illustrated with the two parts of its production and storage, as shown in Figure 6. After receiving the orders, the production need to develop production scheduling, and the warehouse need to arrange storage location. However, the production process or storage process often occurs dynamic, such as product line early or delay, equipment failure, workers absenteeism, the storage location unavailable etc. It lead to that the scheduling and the storage location planning results are poor, and the cost of PL operation is high. To solve above problems, the author's project team has done two aspects of work. First, according to the operation process of the company PL, using Internet of things and CM technology to develop a PL management system interconnect between workshop and warehouse, and realize the transparency of management; Second, this paper studies the PLS optimization method is applied to above two links. This section focuses on the second part of the research.

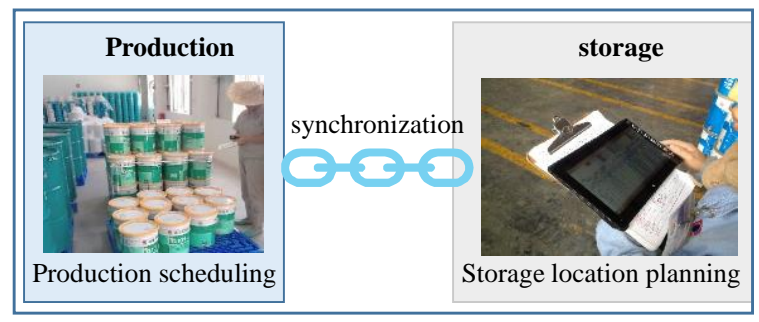

Fig. 5. Production and storage synchronization

\subsection{Collaborative Optimization Model}

This case is based on the synchronization between production and storage (i.e., production scheduling and storage planning) and the $\mathrm{CO}$ model is established. 


\section{System Model.}

The system model can be established as follows.

$$
\begin{gathered}
\min F=t_{1}+t_{2} \\
\text { Subject to } J_{1}=\left(t_{11}-t_{1}\right)^{2} \leq \varepsilon \\
J_{2}=\left(t_{22}-t_{2}\right)^{2} \leq \varepsilon
\end{gathered}
$$

The objective function (6) is the minimum customer waiting time. Constraint (7) and (8) are system consistency constraints, $t_{11}$ is the system level design variable for the production subsystem, $t_{22}$ is the system level design variable for the storage subsystem, $t_{1}$ and $t_{2}$ are system level design variables.

\section{Production Subsystem Model.}

In this case, the production subsystem optimization problem is how to plan the orders processing sequence on the equipment, so that the production task completion time

\begin{tabular}{|c|c|c|c|}
\hline Variable & definition & Variable & definition \\
\hline $\bar{i}$ & Order number & $\bar{i}$ & Process number \\
\hline$K_{i}$ & $\begin{array}{l}\text { Processing unit number } \\
\text { of order } i\end{array}$ & $D_{i j}$ & $\begin{array}{l}\text { Equipment number of the pro- } \\
\text { cess } j \text { for order } i\end{array}$ \\
\hline$W T_{i j}$ & $\begin{array}{l}\text { The processing time of } \\
\text { the process } j \text { on the } \\
\text { equipment for the order } i\end{array}$ & $x_{i j k d}$ & $\begin{array}{l}\text { The processing unit }(i, j, k) \text { on } \\
\text { the equipment } D_{i, j} \text { processing } \\
\text { and the value is } 1 \text {, else is } 1 \text {. }\end{array}$ \\
\hline $\mathrm{T}_{f_{i j k}}$ & $\begin{array}{l}\text { The time of processing } \\
\text { start and end }\end{array}$ & $N_{t_{i j k}}$ & $\begin{array}{l}\text { The next processing time after } \\
\text { the processing unit }(i, j, k) \text { in } \\
\text { the equipment. }\end{array}$ \\
\hline
\end{tabular}
is shortest. According to the practical of production, the variables shows in table 1.

Table 1. Variables and definition

Following the above parameters and variables, a mathematical model of production scheduling could be established as follows.

$$
\begin{gathered}
\min \mathrm{f}=\left\{\max _{\forall d \in D}\left\{\max _{\forall i \in I, j \in J, k \in K_{i}}\left\{x_{i j k d} * T_{f_{i j k}}\right\}\right\}\right\} \\
\text { Subject to } \quad \sum_{d \in D_{i j}} x_{i j k}=1, \forall i \in I, j \in J, k \in K_{i} \\
\mathrm{~T}_{f_{i j k}}-\mathrm{T}_{b_{i(j+1) k}}<0 \forall i \in I, j \in\{1,2\}, \mathrm{k} \in K_{i} \\
T_{f_{i j k}}-T_{b_{i j k}}=W T_{i j} \forall i \in I, j \in J, k \in K_{i} \\
N_{t_{i j k}}-T_{f_{i j k}}>0 \forall i \in I, j \in J, \mathrm{k} \in K_{i}
\end{gathered}
$$

The objective function (9) is the minimum completion time of a batch of orders, 
$\max _{\forall i \in I, j \in J, k \in K_{i}}\left\{x_{i, j, k, d} * T_{f_{i, j, k}}\right\}$ means the completion time for all processing units on the equipment $D, \max _{\forall d \in D}\left\{\max _{\forall i \in I, j \in J, k \in K_{i}}\left\{x_{i, j, k, d} * T_{f_{i, j, k}}\right\}\right\}$ means the completion time of all processing units for all the equipment. Constraint (10) defines that a processing element is allocated to an equipment. Constraint (11) gives that only before the neck of the order has processed and then the after the neck of the order can be processed. Constraint (12) defines that once a processing unit begins processing and cannot be interrupted. Constraint (13) guarantees that only after the current task is finished and the next task can be started by the equipment.

\section{Storage Subsystem Model.}

In this case, the storage subsystem optimization problem is how to distribution the storage location for the order and make the utilization rate of the warehouse is the highest, and its parameters and variables shown in table 2.

Table 2. Variables and definition

\begin{tabular}{|c|c|c|c|}
\hline Variable & definition & Variable & definition \\
\hline$t$ & $\begin{array}{l}\text { Time list of waiting } \\
\text { input order }\end{array}$ & $\bar{j}$ & Storage location number \\
\hline$i$ & Order of waiting input & $V_{j}$ & Capacity of storage location $j$ \\
\hline$Q_{i}$ & $\begin{array}{l}\text { Quantity of pallets for } \\
\text { order } i\end{array}$ & $E_{j}$ & $\begin{array}{l}\text { Consumption time of output from } \\
\text { storage location } j\end{array}$ \\
\hline$I T_{i}$ & $\begin{array}{l}\text { Input time number for } \\
\text { order } i\end{array}$ & $x_{i j}^{t}$ & $\begin{array}{l}\text { Time list } t \text { put the order } i \text { in the } \\
\text { storage location } j \text { or not, the value } \\
\text { is } 0 \text { or } 1 \text {. }\end{array}$ \\
\hline$O T_{i}$ & $\begin{array}{l}\text { Output time number } \\
\text { for order } i\end{array}$ & $w_{i j}^{t}$ & $\begin{array}{l}\text { The } w_{i j}^{t}=1 \text { means the quantity } \\
\text { pallet of order } i \text { in the storage lo- } \\
\text { cation } j \text {, if } x_{i j}^{t}=0 \text {, then } w_{i j}^{t}=0 \text {. }\end{array}$ \\
\hline
\end{tabular}

Following the above parameters and variables, a multi-objective model of storage location layout could be established as follows.

$$
\begin{gathered}
\min f_{1}=\sum_{j=1}^{L} U_{t}^{j} \\
\max f_{2}=\sum_{j=1}^{L} F_{t}^{j} \\
\max f_{3}=\sum_{t=1}^{T} \sum_{j=1}^{L} \sum_{i=1}^{S}\left(E_{j} x_{i j}^{t} w_{i j}^{t}\right) \\
\text { Where } F_{t}^{j}=\left\{\begin{array}{rr}
1, x_{a j}^{t} w_{a j}^{t}+x_{b j}^{t} w_{b j}^{t}=V_{j}, \mathrm{j}=1,2, \ldots, \mathrm{L}, \\
\text { and } \mathrm{a}, \mathrm{b}=1,2, \ldots, \mathrm{S}
\end{array}\right.
\end{gathered}
$$




$$
\begin{gathered}
U_{t}^{j}=\left\{\begin{array}{c}
1, x_{a j}^{t} w_{a j}^{t}+x_{b j}^{t} w_{b j}^{t}>0_{j}, \mathrm{j}=1,2, \ldots, \mathrm{L}, \\
\text { and } \mathrm{a}, \mathrm{b}=1,2, \ldots, \mathrm{S}
\end{array}\right. \\
0 \quad \begin{array}{r}
\mathrm{j} \\
\text { Subject to } \quad \sum_{\mathrm{j}=1}^{L} x_{i j}^{t} \leq 2 \quad \mathrm{j}=1,2, \ldots, \mathrm{L} ; \mathrm{t}=0,1,2, \ldots, \mathrm{T}
\end{array} \\
\sum_{a, b=1}^{S} x_{a j}^{t} w_{a j}^{t}+x_{b j}^{t} w_{b j}^{t} \leq V_{j}, \mathrm{j}=1,2, \ldots, \mathrm{L} ; \mathrm{t}=0,1,2, \ldots, \mathrm{T} \text { and } \mathrm{a} \neq \mathrm{b} \\
\sum_{\mathrm{j}=1}^{L} x_{i j}^{t} w_{i j}^{t}=P_{i}, i=1,2, \ldots, S \text { and } \mathrm{t}=0,1, \ldots, \mathrm{T}
\end{gathered}
$$

The objective function (14) is the minimum total quantity of storage location. The objective function (15) is the maximum times of full storage location. The objective function (16) is the maximum loading efficiency. Constraint (17) ensures the quantity of each storage location puts orders no more than two. Constraint (18) defines the total number of pallets cannot exceed the capacity of the storage location. Constraint (19) gives the total quantity of pallets for sales order.

\section{Structure of Model.}

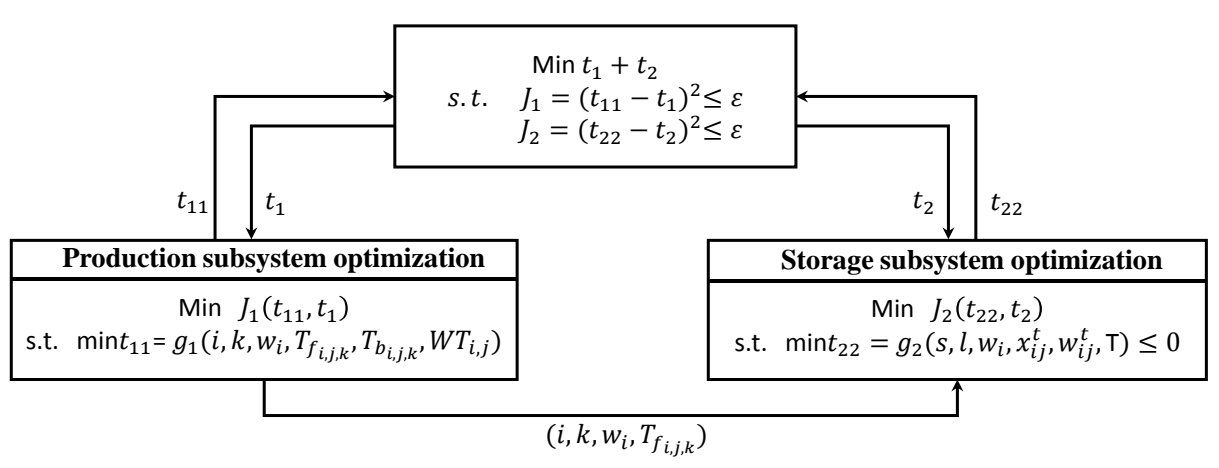

Fig. 6. Structure of production and storage $\mathrm{CO}$ model

The structure of Co model is shown in Figure 6. The collaborative between system level and subsystem level is $t_{1}, t_{2}, t_{11}, t_{22}$. The system initial variables is $t_{1}, t_{2}$. Where $t_{11}$ is a collaborative variable for the production subsystem which indicates the completion time of a batch of order, $t_{22}$ is a collaboration variable for the storage subsystem which means the order at the warehouse time.

The $\left(i, \mathrm{k}, T_{f_{i, j, k}}, w_{i}\right)$ is the array between production subsystem and the storage subsystem, The variable of the array contains the order number, the order processing unit, the processing completion time, and the number of pallets. These variables are the input parameters of the storage subsystem. Based on these input parameters, the storage subsystem obtains the most reasonable distribution results. Each subsystem involves only its local constraints, on the basis of meeting constraints, and its goal is to reduce the differences between the system level and the system level as far as possible. The system level optimization problem has two consistency constraints, and are respectively 
corresponding to two subsystems.

\subsection{Example}

Initial Information.

The initial data of this example comes from the company. The order information is shown in Table 3 and the warehouse information is shown in Table 4.

Table 3. Order information

\begin{tabular}{clll}
\hline $\begin{array}{c}\text { Order } \\
\text { Number }\end{array}$ & $\begin{array}{c}\text { Demand quantity } \\
(\mathrm{t})\end{array}$ & $\begin{array}{c}\text { Processing time } \\
(\mathrm{min})\end{array}$ & $\begin{array}{c}\text { Tray quantity of } \\
\text { Product }\end{array}$ \\
\hline 1 & 1.5 & $80 / 120 / 70$ & 19 \\
2 & 2 & $90 / 100 / 80$ & 25 \\
3 & 1 & $80 / 90 / 75$ & 13 \\
4 & 1.5 & $80 / 70 / 90$ & 19 \\
5 & 1 & $100 / 110 / 100$ & 13 \\
6 & 2 & $90 / 100 / 80$ & 25 \\
\hline
\end{tabular}

Table 4. Warehouse information

\begin{tabular}{lllll}
\hline $\begin{array}{c}\text { Storage Location } \\
\text { Number }\end{array}$ & Name & capacity & area & $\begin{array}{c}\text { Outbound } \\
\text { efficiency }\end{array}$ \\
\hline 1 & A1 & 20 & Dispatch area & 2 \\
2 & A2 & 20 & Dispatch area & 2 \\
3 & A3 & 20 & Dispatch area & 2 \\
4 & A4 & 20 & Dispatch area & 2 \\
5 & A5 & 20 & Dispatch area & 2 \\
6 & B1 & 8 & Full area & 1 \\
7 & B2 & 8 & Full area & 1 \\
8 & B3 & 8 & Full area & 1 \\
\hline
\end{tabular}

\section{Results Analysis.}

The initial values of the parameters $t_{1}$ and $t_{2}$ of the 5.1 sections are set 0 , the relaxation variable $\varepsilon$ is set $10^{-4}$, and the initial information is brought into the mathematical model. The results of the calculation are shown on the left of Table 5 by the Matlab software. To illustrate the effectiveness of PLS optimization method, this paper chooses the deterministic optimization method for comparison. Its calculation results are shown on the right of Table 5 .

From the results can be seen, In terms of storage location occupancy, all the pallets take up 7 storage location of the total which the warehouse adopt the PLS optimization method, and the storage location B3 is empty. While the warehouse adopt the deter- 
ministic optimization method, total takes up 8 storage location, and all the storage location are taken up. In terms of the full times of storage location, all the storage locations are full by PLS optimization method, but the quantity of full storage location is 7 , and storage location A4 is not full by deterministic optimization method. From the results of the comparison, it can be seen that the production and storage synchronization method can improve the utilization of the storage location.

Table 5. Storage subsystem optimization Results

\begin{tabular}{|c|c|c|c|c|c|c|c|}
\hline \multirow{2}{*}{$\begin{array}{l}\text { Order } \\
\text { number }\end{array}$} & \multirow{2}{*}{$\begin{array}{l}\text { Tray } \\
\text { quantity }\end{array}$} & \multicolumn{3}{|c|}{$\begin{array}{c}\text { PLS } \\
\text { optimization method }\end{array}$} & \multicolumn{3}{|c|}{$\begin{array}{c}\text { Deterministic } \\
\text { optimization method }\end{array}$} \\
\hline & & $\begin{array}{l}\text { Input } \\
\text { list }\end{array}$ & $\begin{array}{l}\text { Output } \\
\text { list }\end{array}$ & $\begin{array}{l}\text { Storage } \\
\text { location }\end{array}$ & $\begin{array}{l}\text { Input } \\
\text { list }\end{array}$ & $\begin{array}{l}\text { Output } \\
\text { list }\end{array}$ & $\begin{array}{l}\text { Storage } \\
\text { location }\end{array}$ \\
\hline 1 & 19 & 5 & 6 & A5 & 3 & 3 & A3 \\
\hline 2 & 25 & 3 & 4 & $\mathrm{~A} 3 / \mathrm{B} 1$ & 2 & 4 & $\mathrm{~A} 2 / \mathrm{B} 1$ \\
\hline 3 & 13 & 2 & 2 & A2 & 2 & 1 & B1/B2/B3 \\
\hline 4 & 19 & 1 & 1 & $\mathrm{~A} 1$ & 1 & 2 & A1 \\
\hline 5 & 13 & 4 & 3 & $\mathrm{~A} 2 / \mathrm{B} 1, \mathrm{~B} 2$ & 4 & 4 & A4 \\
\hline 6 & 25 & 3 & 5 & $\mathrm{~A} 4 / \mathrm{B} 2$ & 5 & 6 & A5/B3 \\
\hline
\end{tabular}

\section{Conclusion}

Synchronization mechanism and the optimization method is proposed in this paper to solve the dynamic production logistics problem of production logistics operation of the among production logistics multiple-subsystems. The dynamic of production logistics is divided into local dynamic, the global dynamic, first level dynamic and second level dynamic. For different dynamic, from the qualitative point of view, the PLS mechanism and cloud-based PLS information architecture are proposed. From the quantitative point of view, CO-based PLS optimization method is proposed. Finally, based on example of an enterprise of production and storage, establish optimization model of synchronization of production and storage, and the results show that the proposed method enhances the utilization of the goods. The methods of this paper have practical guidance for solving the problem of the dynamic problem of the operation of production logistics. In the future, the method for synchronization problem of multiple-subsystems of difficult PL dynamic and is studied.

\section{Acknowledgement}

This work was supported by the National Natural Science Foundation of China (51475095), 2014 “Thousand-Hundred-Ten" Scheme of Guangdong Education Department, National Science and Technology Ministry of China (2012BAF12B10). We would also like to thank Carpoly Chemical Group Co., Ltd. for their financial support to this project and the opportunity of system testing and implementing in their factories. 


\section{References}

1. Samaranayake, P., Toncich, D.: Integration of production planning, project management and logistics systems for supply chain management. International Journal of Production Research, 45 (22), 5417-5447 (2007)

2. T. Qu, S. P. Lei, Z. Z. Wang, D. X. Nie, X. Chen, George Q. Huang.: IoT-based real-time production logistics synchronization system under smart cloud manufacturing, The International Journal of Advanced Manufacturing Technology (2015)

3. Li, B.H., Zhang, L., Wang, S.-L., Tao, F., Cao, J., Jiang, X., Chai, X.: Cloud manufacturing: a new service-oriented networked manufacturing model. Computer Integrated Manufacturing Systems. 16(1), 1-7 (2010)

4. Tao, F., Zhang, L., Venkatesh, V. C., Luo, Y., Cheng, Y.: Cloud manufacturing: a computing and service-oriented manufacturing model. Proceedings of the Institution of Mechanical Engineers, Part B: Journal of Engineering Manufacture (2011)

5. Xu, X.: From cloud computing to cloud manufacturing. Robotics and Computer-Integrated Manufacturing. 28(1), 75-86 (2012)

6. Wang, Xi Vincent, and X. W. Xu.: An interoperable solution for Cloud manufacturing. Robotics and Computer-Integrated Manufacturing. 29(4),232-247 (2013)

7. Ren, L., Zhang, L., Tao, F., Zhao, C., Chai, X., Zhao, X.: Cloud manufacturing: from concept to practice. Enterprise Information Systems. (ahead-of-print), 1-24 (2013)

8. Braun, R.: Collaborative Optimization: An Architecture for large-scale distributed design, doctoral dissertation, Stanford University. (1996)

9. Tappeta, R., and Renaud.: Multi objective collaborative optimization. ASME J. Mech. Des. 119(3), 403-411(1997)

10. Zhang, Y., Qu, T., Ho, O., Huang, G. Q.: Real-time work-in-progress management for smart object-enabled ubiquitous shop-floor environment. International Journal of Computer Integrated Manufacturing. 24(5), 431-445 (2011)

11. Alexandrov, N M., and Lewis R M.: Analytical and computational aspects of collaborative optimization for multidisciplinary design. AIAA journal. 40(2), 301-309 (2002) 